ISSN: 2594-4827

\title{
ASPECTOS GERAIS DA PEDAGOGIA HISTÓRICO-CRÍTICA
}

Lucas Antonio Feitosa de Jesus ${ }^{1}$

Juliane dos Santos ${ }^{2}$

Luiz Gustavo da Silva Bispo Andrade ${ }^{3}$

\section{RESUMO}

Neste artigo buscou-se elaborar um quadro geral sobre os pontos substanciais da Pedagogia Histórico-Crítica. Desenvolvida pelo filósofo e educador Dermeval Saviani (1943-), a Pedagogia Histórico-Crítica assenta-se na proposta de contextualização do saber sistematizado à realidade da prática social. Partindo-se de uma perspectiva sincrética do conhecimento, pretende-se chegar ao concreto pensado através de procedimentos que envolvam a problematização e a instrumentalização teórico-prática onde os alunos, com a mediação do professor, entrarão em contato com o saber construído historicamente, objetivando-se, ao fim, a conversão desses alunos em agentes ativos da transformação social. Neste artigo, mediante levantamento bibliográfico composto majoritariamente por autores marxistas, foram descritos três dos principais pilares da Pedagogia Histórico-Crítica: o trabalho, compreendido como princípio da educação; o materialismo histórico-dialético, entendido como uma abordagem específica para essa pedagogia e para a interpretação do real; e a síntese, concebida como objetivo e finalidade da Pedagogia Histórico-Crítica, a ser obtida através da perspectiva analítica da realidade.

Palavras-chave: Educação marxista. Pedagogia transformadora. Ensino crítico.

\section{ABSTRACT}

In this article we tried to elaborate an general view about the Historical-Critical Pedagogy. Developed by the philosopher and educator Dermeval Saviani (1943-), the Historical-Critical Pedagogy is based on the purpose of contextualization of the systematized knowledge to the reality of social practice. Starting from a syncretic perspective of knowledge, we intend to arrive at the concrete thought through procedures that involve the problematization and theoretical- practical instrumentalization where the students, through the teacher's mediation, will come into contact with the knowledge historically constructed, aiming the conversion of these students into active persons on the social transformation. Here, through bibliographical survey composed mostly of marxist autors, we described three of the most important pillars of Historical-Critical Pedagogy: Work, understood as the principle of education; HistoricalDialetic Materialism, understood as a specific approach to this pedagogy and to the interpretation of the real; and the synthesis, conceived as the ultimate goal of the HistoricalCritical Pedagogy, to be obtained through the analytical perspective of reality.

Keywords: Marxist education. Pedagogy for transformation. Critical education.

\footnotetext{
${ }^{1}$ Instituto Federal de Sergipe. E-mail: 1.a.f.j@hotmail.com

${ }^{2}$ Instituto Federal de Sergipe. E-mail: julianesantos.ufs@ gmail.com

${ }^{3}$ Instituto Federal de Sergipe. E-mail: luiz.gustavosb2016@ gmail.com
} 


\section{INTRODUÇÃO}

De acordo com Petenucci (2008), tendências pedagógicas podem apontar para um caminho diferente daquele no qual o cotidiano escolar está inserido: falta de interesse dos educandos, aulas pouco significativas, conhecimentos descolados da realidade, etc. Questiona- se o papel da escola nos tempos hodiernos. Diferentes métodos pedagógicos tendem a se basear em movimentos sociais, filosóficos e antropológicos que correspondem aos anseios da sociedade e ao momento histórico por ela vivida, propondo mudanças e alterando a prática educativa de modo que o ensino passe a ser algo que complemente as experiências empíricas diárias vividas pelos alunos.

A Pedagogia Histórico-Crítica é uma prática pedagógica que visa trabalhar o saber sistematizado transformando-o em saber significativo de modo que, no processo de transmissão e assimilação, o aluno seja capaz de realizar conexões relevantes entre as diversas disciplinas e a realidade contextual à qual ele faz parte, entendendo o conhecimento como historicamente elaborado. Esse processo parte da defesa pela escola, compreendida como uma instituição estabelecida histórico-socialmente sendo a responsável pela socialização do saber sistematizado. É na escola que a Pedagogia Histórico-Crítica se enraíza, ainda que seus efeitos não sejam limitados a ela, mas estejam voltados para a prática social global.

Descrita no ano de 1982 por Dermeval Saviani no artigo Para além da teoria da curvatura da vara, número 3 da Revista da Ande (SAVIANI, 2011), a Pedagogia HistóricoCrítica não recebeu prontamente essa denominação. Antes, Saviani utilizou os termos "Pedagogia Dialética" e "Pedagogia Revolucionária" para reproduzir um ponto de vista que não se preocupava apenas em descrever os mecanismos através dos quais a escola não funciona de modo satisfatório, entendendo seu fracasso como único destino possível. Pelo contrário, o objetivo do autor era propor uma prática pedagógica aplicada a um conceito dialético de escola no qual esta é determinada pela infraestrutura e pelas superestruturas da formação social onde ocorre mas que, ao mesmo tempo, as determina (GERALDO, 2014). A escola influencia a sociedade e ao mesmo tempo é influenciada por ela. Desta forma, tendo como paradigma o materialismo histórico-dialético, em 1984, Saviani denomina seu método de "Pedagogia Histórico-Crítica". 
Este artigo buscou fazer um levantamento bibliográfico de autores, marxistas em sua maioria, que trataram de modo direto ou indireto a questão da Pedagogia Histórico-Crítica. Através do conceito de trabalho, da compreensão do materialismo histórico-dialético e da análise do conhecimento em síntese, foi traçado um panorama geral sobre esta Pedagogia.

\section{O TRABALHO COMO GÊNESE}

A categoria trabalho é polissêmica. Conforme Frigotto (2009), a dinâmica das relações sociais ao longo do tempo dotou esta categoria de significados diversos, ora conflitantes, separando-a progressivamente do seu sentido originário. Fundamentalmente pautada pelos ditames hegemônicos, as diversas maneiras com as quais o trabalho se apresenta resulta de mediações dimensionadas pela natureza histórico-social, ontológica e ético-política às quais essa categoria está submetida.

Fazendo um breve preâmbulo da perda do significado original dessa categoria, Saviani (1989, 2007) afirma que o trabalho é uma atividade especificamente humana. A partir do momento em que o ser humano surge, emerge também a necessidade de produzir a própria vida. A natureza bravia e inóspita que o cercava precisava ser dominada, modificada e adaptada para as necessidades humanas. Em suma, é na relação do homem com a natureza, com a transformação desta por meio do trabalho, que a humanidade se autocria.

Ora, o ato de agir sobre a natureza transformando-a em função das necessidades humanas é o que conhecemos com o nome de trabalho. Podemos, pois, dizer que a essência do homem é o trabalho. A essência humana não é, então, dada ao homem; não é uma dádiva divina ou natural; não é algo que precede a existência do homem. Ao contrário, a essência humana é produzida pelos próprios homens. O que o homem é, é-o pelo trabalho. A essência do homem é um feito humano. É um trabalho que se desenvolve, se aprofunda e se complexifica ao longo do tempo: é um período histórico (SAVIANI, 2007, p. 154).

O modo de produção comunal representou uma união inconteste entre educação e trabalho, na qual ambas se confundiam. O próprio ato existir, mediante a ação de apropriação coletiva dos meios de produção, correspondia ao ato de o homem se formar homem, de se educar. Nesta perspectiva, é válido lembrar que Gramsci (apud MOURA; LIMA FILHO; SILVA, 2015) subscrevia a organicidade entre trabalho e educação, localizando-a como 
processo através do qual o ser humano obtém suas próprias condições de humanização em um processo circunstanciado pela história e pelos modos de produção de existência.

Saviani (1989) esclarece que, com o avançar do processo histórico, essa noção orgânica entre trabalho e educação foi perdendo sentido. Graças ao advento das sociedades escravista e feudal, as classes dominantes apossaram-se dos meios de produção, ampliando seus poderes por intermédio da exploração das classes trabalhadoras. Neste contexto, o surgimento de setores sociais ociosos, sem a obrigação do desenvolvimento de atividades laborais para garantir a própria sobrevivência, fez emergir a escola, tendo esta se tornado a principal forma de educação muito embora fosse garantida apenas para uma parcela diminuta da sociedade. Com o avançar das forças produtivas e do consequente acúmulo de capital, duas classes foram estabelecidas: a burguesia, detentora dos bens de produção; e o proletariado, que vende sua força de trabalho como forma de obter salário. Conforme Geraldo (2014), o desenvolvimento da sociedade contemporânea acompanha a generalização da educação escolar, sendo esta a principal responsável pela socialização dos conhecimentos sistematizados, científicos e tecnológicos, que passam a ser uma condição sine qua non às relações sociais e de produção. É estabelecida a separação entre trabalho e educação.

É com o desenvolvimento das relações sociais produtivistas capitalistas que o trabalho assume o sentido de emprego remunerado e trabalhador para designar a classe trabalhadora (...). A redução do trabalho de atividade vital do ser humano para produzir seus meios de vida a emprego vincula-se, pois, a uma dupla determinação: o desenvolvimento concomitante da palavra trabalho, do termo emprego e das relações sociais dominantes (FRIGOTTO, 2009, p. 175).

A base da sociedade capitalista está assentada na divisão entre proprietários de meios de produção e os detentores da força de trabalho. Essa divisão do trabalho promove uma consequente divisão do conhecimento com o advento de disciplinas científicas autônomas que visam atender às demandas de fragmentação de funções na sociedade com diferentes profissões (SAVIANI, 1989). Borges e Dalberio (2007), criticando a escola tradicional, afirmam que, no Brasil, o paradigma positivista norteou hegemonicamente o sistema educacional com a implementação de disciplinas isoladas e desconexas entre si e com a realidade, tornando o processo de aprendizagem repetitivo, pobre e fragmentado. A mera 
transmissão de um conhecimento sistematizado, porém, segmentado em partes independentes, não deixa espaço para a emergência de uma aprendizagem significativa aos educandos.

Uma vez que a formação humana integral com base no conceito pleno de politecnia de Marx e Engels e o princípio educativo da escola unitária de Gramsci "referem-se a uma possibilidade futura a ser materializada em uma sociedade na qual a classe trabalhadora tenha ascendido ao poder político" (MOURA; LIMA FILHO; SILVA, 2015, p. 1066), a Pedagogia Histórico-Crítica caracteriza-se como uma ponte para esses objetivos, tendo sido elaborada para implementação nas condições atuais da sociedade brasileira - onde a predominância do saber fragmentado é a regra - com vistas à superação da divisão do saber (SAVIANI, 1999). Para Saviani (2011), a Pedagogia Histórico-Crítica mantém íntima relação com a realidade escolar presente, sendo esta a raiz de sua origem e tendo sido pensada para as problemáticas hodiernas e comuns a educadores e educandos. Como será tratado no quarto tópico deste trabalho, a Pedagogia Histórico-Crítica visa atingir a omnilateralidade, a visão sintética da realidade, mediante a condição analítica que a escola se apresenta e com a interpretação sincrética que os alunos possuem do conhecimento nela estabelecido.

Mas, eu não posso também primeiro transformar a educação para transformar a sociedade, porque para a educação se transformar é preciso que a sociedade se transforme. Então, deve-se partir da situação atual, ou seja, eu parto do existente e busco realizar a transformação, concomitantemente, dos dois aspectos. É preciso, pois, partir da situação existente (SAVIANI, 1989, p. 32).

A Pedagogia Histórico-Crítica, portanto, compreende a escola enquanto um campo ideológico que reproduz uma visão de mundo vinculada aos interesses hegemônicos dos grupos sociais dominantes (ARAÚJO; FRIGOTTO, 2015) mas apropria-se desse sistema transformando-o desde a base, redirecionando o foco até então centrado na perspectiva imediatista do mercado para a prática social guiada pela síntese do conhecimento sistematizado com a realidade. Geraldo (2014, p. 22 e 23) cita como ocupação da Pedagogia Histórico-Crítica "sistematizar o conhecimento sobre as práticas educativas, identificando sua especificidade no conjunto das práticas sociais, suas finalidades, suas formas, seu movimento, seu desenvolvimento". 
Essa transformação é o processo por meio do qual se selecionam, do conjunto do saber sistematizado, os elementos relevantes para o crescimento intelectual dos alunos e organizam-se esses elementos numa forma, numa sequência tal que possibilite a sua assimilação. Assim, a questão central da pedagogia é o problema das formas, dos processos, dos métodos; certamente, não considerados em si mesmos, pois as formas só fazem sentido quando viabilizam o domínio de determinados conteúdos (SAVIANI, 2011, p. 65).

Atuando nas condições atuais da escola brasileira e propondo uma retomada às condições de ensino e aprendizagem em sentido pleno, a Pedagogia Histórico-Crítica pretende resgatar aquela condição de unidade indissolúvel entre trabalho e educação. De acordo com Geraldo (2014), um dos principais postulados da Pedagogia Histórico-Crítica consiste em considerar a educabilidade humana como forma derivada do desenvolvimento do trabalho produtivo e criativo, da sociabilidade, da comunicabilidade complexa e da racionalidade, desenvolvidos em processo histórico-cultural sendo determinados de maneira recíproca com base no processo de produção da subsistência.

Consequentemente, o trabalho educativo é o ato de produzir, direta e intencionalmente, em cada indivíduo singular, a humanidade que é produzida histórica e coletivamente pelo conjunto de homens. Assim, o objeto da educação diz respeito, de um lado, à identificação dos elementos culturais que precisam ser assimilados pelos indivíduos da espécie humana para que eles se tornem humanos e, de outro lado e concomitantemente, à descoberta das formas mais adequadas para atingir esse objetivo (SAVIANI, 2011, p. 13).

Como será visto mais à frente, a prática social é tanto o ponto de partida como o ponto de chegada da Pedagogia Histórico-Crítica. Por prática social entende-se o conhecimento teórico e prático baseado na vivência do educando e do professor a respeito de determinado tema (PETENUCCI, 2008). Estes saberes em ato e em potência - ponto de partida e da chegada da prática social, respectivamente - constituem, segundo Saviani (2011), o "trabalho não material", onde o produto não se separa do produtor. Entender educação e trabalho em uma relação dialética é o ponto de partida para a Pedagogia Histórico-Crítica. 


\section{O MATERIALISMO HISTÓRICO-DIALÉTICO EPISTEMOLÓGICA}

\section{COMO POSTURA}

De acordo com Kuenzer e Grabowsk (2016) e Borges e Dalberio (2007), existem pelo menos três posturas epistemológicas que balizam a compreensão e o entendimento da realidade: o positivismo, a fenomenologia e o materialismo histórico-dialético. A primeira, como já foi supracitada no tópico anterior, pauta o sistema educacional brasileiro comungando com as ideias do liberalismo e servindo à classe dominante através de um processo analítico contínuo de fragmentação do conhecimento. A fenomenologia, por sua vez, tenta conceber a essência dos fenômenos de modo independente à realidade que os cerca. Para os fenomenologistas, a realidade deve ser descrita de forma pura, como ela de fato é, sem objetivar mudanças estruturais profundas. Nessa perspectiva a-histórica, as investigações sobre a escola e o currículo escolar tornam-se irrelevantes, uma vez que dispensa-se uma leitura crítica sobre os alicerces da ideologia dominante e sua necessária superação.

O materialismo histórico-dialético distingue-se dos demais, pois, considera a história como a única realidade possível, sendo ela dinâmica, não linear e pautada pelos aspectos materiais que são, ao mesmo tempo, determinantes e determinados. A história, portanto, é uma luta de contrários movida pelo imanente conflito da realidade (SEVERINO, 2016). Conforme Gil (2008), a dialética foi inicialmente usada por Platão para designar a arte do diálogo e, durante a Idade Média, foi sinônimo de lógica. O moderno uso da dialética, o momento em que ela se estabelece como concepção, aparece em Hegel, onde se dispõe do termo em um prisma idealista, considerando que "a cultura fazia a história mover-se no âmbito do espírito absoluto" (SAVIANI, 2011, p. 53). A conversão do idealismo ao materialismo foi obra de Marx, quando este demonstrou que a sociedade é o resultado da organização dos meios de produção, de sua posterior distribuição entre os seres humanos e da luta travada entre exploradores e explorados (MONDIN, 1980).

Por sua fundamentação, meu método dialético não só difere do hegeliano, mas é também a sua antítese direta. Para Hegel, o processo de pensamento, que ele, sob o nome de ideia, transforma num sujeito autônomo, é o demiurgo do real, real que constitui apenas a sua manifestação externa. 
Para mim, pelo contrário, o ideal não é nada mais que o material, transposto e traduzido na cabeça do homem (MARX, 1996, p. 140).

É exatamente ao aplicar as teses do materialismo dialético à compreensão da vida social e seus fenômenos dinâmicos que se define, também, o materialismo histórico. Borges e Dalberio (2007) afirmam que o Materialismo Histórico é a aplicação da teoria marxista à evolução histórica da existência organizada dos indivíduos, através da qual os bens materiais subordinam e conduzem a vida social, política e intelectual que, ao seu passo, igualmente interagem com a base material. A historicidade é a base desse amálgama.

Por conseguinte, o materialismo dialético pode ser definido como a filosofia do materialismo-histórico, cujo corpo teórico pensa a ciência da história. São quatro os princípios fundamentais do materialismo dialético: 1) a história da filosofia, ao apresentar uma sucessão de doutrinas contraditórias, dissimula um processo em que se apresentam o princípio idealista e materialista; 2) o ser determina a consciência e não o inverso; 3) o contrário da dialética é a metafísica que coloca a matéria como estática, e toda matéria é dialética; 4) a dialética é o estudo da contradição na essência das mesmas coisas (BORGES; DALBERIO, 2007, p. 7).

O materialismo histórico-dialético é a perspectiva a partir da qual os autores marxistas formulam suas teses acerca do homem e de suas extensões sociais. Como alguns exemplos, Saviani (2007, p. 152) afirma que "o ser do homem e, portanto, o ser do trabalho, é histórico"; em outro trabalho, Saviani (1989, p. 49), remetendo-se a Gramsci, defende que "o ser humano é um produto histórico via de regra obtido por coerção", coerção essa exercida por processos histórico-ambientais que redundam no desenvolvimento do homem; Manacorda (1990, p. 148), também fazendo referência a Gramsci, reflete sobre a historicidade da natureza humana que, segundo o filósofo italiano, é do marxismo a descoberta antropológica segundo a qual admite-se que "não existe uma natureza humana fixa e imutável", despindo-se, portanto, do idealismo; Frigotto (2009, p. 168), ao discutir os múltiplos significados da categoria trabalho, informa que seu método de análise será o legado marxista, o qual defende que não é a consciência, a teoria e a linguagem que moldam a realidade histórica, mas que esta produz aquelas, "sendo e tornando- se, porém, elas mesmas parte dessa realidade"; Kuenzer e Grabowsk (2016, p. 23), analisando o problema da Educação Profissional no regime de 
acumulação flexível, admitem que a opção epistemológica escolhida foi a dialética marxista uma vez que "essas categorias ${ }^{4}$ só podem ser compreendidas na materialidade das relações de produção nas quais se inserem".

Com a Pedagogia Histórico-Crítica, empenhada em dispor a educação a serviço das transformações necessárias às relações de produção, não é diferente. Em Escola $e$ Democracia, Saviani (1999) discute a possibilidade de uma prática educativa que desarticule os interesses da classe dominante rearticulando-os aos desígnios dos dominados. Para tal, o autor faz uma espécie de exegese para explicar os motivos pelos quais as teorias educativas vigentes não correspondiam a essa necessidade. Inicia-se descrevendo as teorias não-críticas, representadas pela Pedagogia Tradicional, pela Pedagogia Nova e pela Pedagogia Tecnicista que, considerando a educação - e, consequentemente, a escola - como um fenômeno independente dos determinantes sociais, acabavam por reforçar as condições de dominação. Em seguida, são descritas as teorias crítico-reprodutivistas, identificadas pela Teoria do Sistema de Ensino enquanto Violência Simbólica de Bourdieu e Passeron (1975), pela Teoria da Escola enquanto Aparelho Ideológico de Estado de Althusser e pela Teoria da Escola Dualista de Baudelot e Establet (1971). Estas teorias são consideradas críticas pois consideram que o estudo da educação passa pela compreensão de seus determinantes sociais. No entanto, além de não possuírem uma proposta pedagógica, entendem que a educação necessariamente reproduz a exploração e a dominação vigentes, não sendo possível, nas configurações atuais da sociedade, vislumbrar qualquer alteração nas estruturas sociais. A educação e a escola são completamente dependentes da sociedade capitalista.

A crítica elaborada pelas teorias reprodutivistas não resolve o problema da educação e, além disso, apresenta um conformismo aos dominantes. É fundamental, pois, pensar em uma escola como realidade histórica profundamente marcada pela intencionalidade da ação humana. Para Saviani (1999), a escola, enquanto parte integrante da sociedade, sofre as influências dos efeitos produzidos pelo modo de produção capitalista; porém, ao mesmo tempo, essa mesma escola relaciona-se dialeticamente com a sociedade e, por conseguinte, pode interferir e minorar a exploração. A escola, enquanto realidade construída historicamente, torna-se de extrema relevância para a Pedagogia Histórico-Crítica por sua

\footnotetext{
${ }^{4}$ Os autores referem-se às categorias de conteúdo e de método, que compõem a Educação Profissional. (KUENZER; GRABOWSK, 2016)
} 
função especificamente educativa e propriamente pedagógica, certificando-a como fundamental para a aprendizagem significativa do saber sistematizado às camadas mais populares.

Uma pedagogia articulada com os interesses populares valorizará, pois, a escola; não será indiferente ao que ocorre em seu interior; estará empenhada em que a escola funcione bem; portanto, estará interessada em métodos de ensino eficazes. Tais métodos se situarão para além dos métodos tradicionais e novos, superando por incorporação as contribuições de uns e de outros (SAVIANI, 1999, p. 79).

Dessa forma, a Pedagogia Histórico-Crítica diferencia-se das visões críticoreprodutivistas uma vez que procura articular orientações pedagógicas que vão além do que a realidade apresenta, enraizando-se na história. Saviani (2011) esclarece que a dificuldade em os crítico- reprodutivistas darem conta das contradições imanentes da sociedade, reside no fato de que estas contradições se ancoram no movimento histórico e, portanto, uma abordagem que se afaste do paradigma histórico-dialético não será capaz de obter com precisão o movimento do real. Em outras palavras, uma pedagogia dialética deve compreender a questão educacional pelo seu desenvolvimento histórico objetivo através da determinação das condições materiais da existência humana.

\section{A SÍNTESE COMO FIM}

Uma prática pedagógica que seja, de fato, crítica, deve agir na realidade com uma atitude transformadora. Araújo e Frigotto (2015) defendem que é fundamental manter uma postura - ainda que utópica - de formação inteira, que se recuse à mera socialização de fragmentos de uma cultura profundamente sistematizada e que compreenda como direito de todos o acesso a um processo de formação que esteja comprometido com o desenvolvimento total das faculdades físicas e intelectuais dos indivíduos. Portanto, uma ação pedagógica engajada tem a missão de desenvolver de modo totalizante as atitudes humanas que vão além do contexto escolar, reverberando no contexto ético e político da vida social. Os saberes sistematizados aliados aos saberes contextuais locais, engendram-se precípuos em uma proposta integradora uma vez que, o educando, munindo-se dos 
conhecimentos escolares específicos em comunhão aos saberes sociais do seu meio, tornase apto a agir criticamente em práticas sociais globais, compreendendo os problemas que lhes são apresentados em sua relação com a totalidade social. A isso se chama de omnilateralidade ou formação omnilateral.

Apreender o real em sua historicidade, em sua evolução, a partir das interações entre as suas mudanças internas e a evolução do contexto onde está inserido. Perguntando- se: como surgiu? Como foi produzido? Em que contexto surgiu? Como se desenvolveu? Como evoluiu? Para que serve? A que ou a quem interessa? Apreender a realidade como totalidade, identificando o contexto espaçotemporal onde está inserido o objeto de estudos, as variáveis que determinam sua existência, o seu movimento e o seu desenvolvimento (GERALDO, 2014, p. 52).

Essa "luta pela utopia do socialismo e da educação omnilateral, unitária e politécnica" (FRIGOTTO, 2009, p. 185) se dá no embate das forças materiais dispostas ao longo da história. Neste processo, a escola tem um papel fundamental. Muito embora a problemática do processo formativo não tenha origens na escola nem efeitos que se limitam a ela, a escola, compreendida com base no desenvolvimento histórico da sociedade, é a instituição dominante da educação com o papel de converter o saber elaborado de modo sistemático (científico, tecnológico, filosófico e artístico) em saber escolar e, a partir dessa conversão, socializar esse saber produzido histórico-socialmente por meio de estratégias de ensino e aprendizagem. Saviani (2011) complementa afirmando que o saber escolar nada mais é senão a organização sequencial e gradual do saber sistematizado disponibilizado em uma determinada etapa histórica com fins de transmissão e assimilação pelos educandos ao longo da vivência escolar.

Com seu ensino, a escola luta contra o folclore, contra todas as sedimentações tradicionais de concepções de mundo, a fim de difundir uma concepção mais moderna, cujos elementos primitivos e fundamentais são dados pela aprendizagem da existência de leis naturais como algo objetivo e rebelde, às quais é preciso adaptar-se para dominá-las, e de leis civis e estatais, produto de uma atividade humana, que são estabelecidas pelo homem e podem ser por ele modificadas tendo em vista seu desenvolvimento coletivo (GRAMSCI, 2001, p. 42-43). 
Neste percurso do ensino formal, para que o processo esteja voltado para "substituir o indivíduo-fragmento, o mero portador de uma função social de detalhe, pelo indivíduo totalmente desenvolvido" (MOURA; LIMA FILHO; SILVA, 2015, p. 1061) alguns princípios precisam ser seguidos:

O compromisso com a formação ampla e duradoura dos homens, em suas amplas capacidades; a ideia de práxis como referência às ações formativas; que a teoria e prática educativa constituam o núcleo articulador da formação profissional; teoria sendo sempre revigorada pela prática educativa; a prática educacional sendo ponto de partida e de chegada; a ação docente se revelando na prática concreta da realidade social (ARAÚJO; FRIGOTTO, 2015, p. 72).

A Pedagogia Histórico-Crítica defende a difusão de conteúdos vivos e atualizados como sendo uma das tarefas primaciais do processo educativo, em sentido extenso, e da escola, em sentido específico. Os procedimentos que pautam essa pedagogia são norteados pela atividade e pela iniciativa dos alunos mas sem perder de vista, também, a iniciativa docente. A ênfase ao diálogo dos alunos entre si e com o professor, valorizando igualmente a troca de ideias com a cultura acumulada historicamente, serão favoráveis ao interesse intelectual dos discentes, aos compassos de aprendizagem e aos desdobramentos cognitivos (SAVIANI, 1999). Todos esses passos não olvidarão do papel de discentes e docentes enquanto agentes sociais nem marginalizarão a necessidade da apropriação do conhecimento lógico e sistemático, bem como sua ordenação cognitiva aos discentes de modo vinculado à realidade que os cercam.

Baseando-se em Saviani (1999), o método da Pedagogia Histórico-Crítica consiste em cinco passos que levam do conhecimento sincrético (empírico) ao concreto pensado (síntese) através da análise: o primeiro passo, comum a docentes e discentes, é a prática social, onde professores e alunos encontram-se em níveis de compreensão diferentes (aqueles, em síntese precária; estes, em absoluta síncrese) uma vez que inserem-se no processo como agentes sociais diferenciados; o segundo passo é a problematização, onde o docente irá detectar quais as questões devem ser resolvidas no contexto da prática social sendo necessário investigar quais conhecimentos serão necessários dominar para tal; o terceiro passo é a instrumentalização, através da qual os discentes irão se apropriar dos 
instrumentos teóricos e práticos - produzidos socialmente e preservados historicamente necessários para a resolução dos problemas da prática social detectados na problematização sendo que o uso desses instrumentos terá a mediação direta ou indireta do professor; o penúltimo passo é a catarse, momento no qual os alunos incorporam ativamente os instrumentos culturais, elaboram um novo conhecimento, expressam uma nova forma de entendimento da prática social e tornam-se agentes ativos da transformação social; o último passo é um retorno à prática social, agora compreendida, pelos alunos, de maneira sintética e significativa, e pelos professores, não mais em uma síntese precária, mas em uma síntese ativa.

O ponto de partida da investigação são as totalidades concretas, mas ainda concebidas como concreto-sensoriais, empiricamente representadas, e o primeiro passo é reduzir a plenitude da representação às suas determinações abstratas, o mais simples, o mais frequente, o mais cotidiano, o que se repete milhões de vezes nas relações observadas (Lênin; "Sobre la dialética", in: Lewis, s/d), é o mesmo momento da regressão; em seguida faz-se a análise detalhada das determinações, das conexões, das contradições, das partes e de suas relações; finalmente faz-se o caminho inverso, da progressão, da síntese, que conduz à reprodução do concreto pela via do pensamento, já agora concreto pensado (GERALDO, 2014, p. 53).

Como foi salientado no segundo tópico deste estudo, assim como o trabalho, a educação é uma atividade coletiva. Por isso, a Pedagogia Histórico-Crítica valoriza os elementos teóricos e práticos na medida em que eles se materializam em uma série de mediações dos alunos entre si, com o professor, com a cultura e com a realidade local. Saviani (2011) reforça que, entendendo a atividade educativa como uma série de mediações que ocorrem no âmbito da prática social global - durante a problematização, a instrumentalização e a catarse -, compreende-se o motivo pelo qual a prática social é o ponto de partida e o ponto de chegada na Pedagogia Histórico- Crítica. Neste processo, da síncrese atinge-se a síntese mediante a análise ou, dito com outras palavras, passa-se do empírico ao concreto pela mediação do abstrato.

A Pedagogia Histórico-Crítica visa alcançar, ao final, o que não estava dado no início do percurso pedagógico aqui tratado. O professor, um agente social que inicia o processo com 
uma síntese ainda que precária, viabiliza a apreensão sintética aos alunos realizando a mediação principal entre o discente e o conhecimento que foi desenvolvido socialmente. Ao final do ciclo, tanto o aluno como o professor estabelecem uma relação sintética com o conhecimento social. Ambos atingem o mesmo patamar e a igualdade, que não está estabelecida no ponto de partida, tem que ser alcançada no ponto de chega (SAVIANI, 2011).

Ora, o conceito de mediação indica, justamente, o caráter instrumental da educação e, por consequência, afirmar que a educação é mediação significa admitir que o que se passa em seu interior não se explica por si mesmo, mas ganha este ou aquele sentido, produz este ou aquele efeito social dependendo das forças sociais que nela atual e com as quais ela se vincula (SAVIANI, 2011, p. 45).

No modelo de escola atual, como foi salientado, o conhecimento está fragmentado em disciplinas. De acordo com a Pedagogia Histórico-Crítica, esse momento corresponde à etapa analítica e, para os alunos, essa noção de aprendizagem desordenada e sem sentido prático diz respeito à visão sincrética da realidade. No conhecimento sincrético está tudo confuso e um tanto quanto caótico. Para se atingir a síntese, deve-se trabalhar as disciplinas em uma visão de totalidade, ou seja, de modo que cada uma comunique-se entre si e elas, juntas, tragam uma aprendizagem significativa a respeito da realidade. Se, como foi dito anteriormente, considera-se a divisão das disciplinas um reflexo no campo educacional daquela divisão que se dá no processo produtivo do trabalho, uma vez que se pretende superar essa divisão e chegar ao concreto pensado, caminha-se também em direção à apropriação coletiva dos meios de produção (ainda que provenientes do trabalho não material) através da apreensão do conhecimento produzido de modo coletivo, do conhecimento global que, articulado à totalidade do real, supera as especializações.

\section{CONSIDERAÇÕES FINAIS}

O presente artigo buscou traçar os aspectos gerais da Pedagogia Histórico-Crítica através do que se considera ser os três pilares fundamentais: sua gênese, seu paradigma e sua finalidade. Através de textos auxiliares e de um levantamento bibliográfico dos principais autores que trataram direta ou indiretamente sobre o tema, foi construída uma noção geral 
sobre esse método pedagógico que possui um alto potencial de exploração em sala de aula, principalmente no contexto da Educação Profissional e Tecnológica.

O trabalho, enquanto gênese dessa pedagogia, representa o momento através do qual o homem adapta a natureza às suas necessidades e os conhecimentos gerados através dessa ação são igualmente socializados entre os partícipes. Na abordagem epistemológica, o materialismo histórico-dialético confirma a necessidade em se compreender o conhecimento como uma construção social através da história que, não sendo independente das estruturas sociais nem completamente imerso nelas, possui uma relação biunívoca de determinação. Por fim, a síntese representa a finalidade da Pedagogia Histórico-Critica onde os envolvidos atingem o concreto pensado, relacionando o conhecimento sistematizado nas instituições escolares à realidade nas quais estão inseridos, tornando-se ativos agentes transformadores da realidade social.

A Pedagogia Histórico-Crítica não é uma obra acabada. Ela é permanentemente construída e reconstruída ao sabor das necessidades sociais que emergem ditadas pelo curso irrefragável da história. Desta forma, seu pleno desenvolvimento deve ser acompanhado por estudos constantes a respeito do tema e, sobretudo, através das práticas in loco de seus princípios uma vez que é apenas no terreno do real, na práxis social, que uma perspectiva pedagógica atinge sua concretude.

\section{REFERÊNCIAS}

ARAÚJO, Ronaldo Marcos de Lima; FRIGOTTO, Gaudêncio. Práticas pedagógicas e ensino integrado. Revista Educação em Questão. Natal, v. 52, n. 38, p. 61-80, mai./ago. 2015.

BORGES, Maria Célia; DALBERIO, Osavaldo. Aspectos metodológicos e filosóficos que orientam as pesquisas em educação. Revista Iberoameciana de Educación. Madrid, v. 5, n. 5, p. 1-10, julho 2007.

FRIGOTTO, Gaudêncio. A polissemia da categoria trabalho e a batalha das ideias nas sociedades de classe. Revista Brasileira de Educação. Rio de Janeiro, v. 14, n. 14, p. 168194, jan./abr 2009.

GERALDO, Antonio Carlos Hidalgo. Didática de ciências naturais na perspectiva histórico- crítica. 2. ed. Campinas: Autores Associados, 2014. 175 p. (Coleção formação de professores). 
GIL, Antonio Carlos. Métodos e técnicas de pesquisa social. 6. ed. São Paulo: Editora Atlas, 2008. 200 p.

GRAMSCI, Antonio. Cadernos do cárcere. 2. ed. Rio de Janeiro: Civilização Brasileira, v. 2, 2001. $334 \mathrm{p}$.

KUENZER, Acácia Zeneida; GRABOWSK, Gabriel. A produção do conhecimento no campo da educação profissional no regime de acumulação flexível. Holos. Natal, v. 6, p. 2232, setembro 2016.

MANACORDA, Mario Alighiero. O princípio educativo em Gramsci. Porto Alegre: Artes Médicas, 1990. 288 p.

MARX, Karl. O Capital: crítica da economia política. São Paulo: Editora Nova Cultural, 1996. $496 \mathrm{p}$.

MONDIN, Battista . Introdução à filosofia: problemas, sistemas, autores e obras. 6. ed. São Paulo: Edições Paulinas, 1980. 323 p.

MOURA, Dante Henrique; LIMA FILHO, Domingos Leite; SILVA, Mônica Ribeiro Politecnica e formação integrada: confrontos conceituais, projetos políticos e contradições históricas da educação brasileira. Revista Brasileira de Educação. Rio de Janeiro, v. 20, n. 63, p. 1057-1080, out./dez. 2015.

PETENUCCI, Maria Cristina. Desvelando a pedagogia histórico-crítica.

Secretaria de Educação do Estado do Paraná. Curitiba, 2008. 26 p. Disponível em: 〈http://www.diaadiaeducacao.pr.gov.br/portals/pde/arquivos/2289-6.pdf>. Acesso em: 15 set. 2018.

SAVIANI, Dermeval. Escola e democracia: teorias da educação, curvatura da vara, onze teses sobre educação e política. 32. ed. Campinas: Autores Associados, 1999. 99 p.

. Pedagogia histórico-crítica: primeiras aproximações. 11. ed.

Campinas: Autores Associados, 2011. 137 p.

. Sobre a concepção de politecnia. Rio de Janeiro: FIOCRUZ, 1989. 51 p.

. Trabalho e educação: fundamentos ontológicos e históricos. Revista

Brasileira de Educação. Rio de Janeiro, v. 12, n. 34, p. 152-165, jan./abr. 2007.

SEVERINO, Antonio Joaquim. Metodologia do trabalho científico. 24. ed. São

Paulo: Cortez, 2016. 317 p. 